\title{
Aproximações entre imagem e palavra nas artes gráficas e visuais
}

\author{
Rubens Rangel Silva* \\ Ângela Cristina Salgueiro Marques**
}

\begin{abstract}
Resumo
Neste artigo propõe-se um estudo das possíveis relações entre imagem e palavra nas artes gráficas e visuais, principalmente a partir das transformações técnicas nos meios de reprodução gráfica, no final do século XIX, com o aprimoramento da litografia e da cromalitografia, e das mudanças na arte no início do século XX, com a dissolução dos limites entre as linguagens artísticas. Reforça-se uma perspectiva de estudo das relações entre os diferentes meios em que são valorizadas não só homologias e similitudes, mas também antagonismos e dissonâncias entre imagem e palavra. Prioriza-se o estudo das interações entre os recursos visuais e verbais, bem como os elementos pictóricos da palavra e os elementos poéticos da imagem, trazendo para reflexão trabalhos de artistas, como Jules Chéret, Pablo Picasso, Paul Klee, Georges Breque, Stéphane Mallarmé, dentre outros. Propõe-se também uma reflexão acerca de como experimentações e montagens entre imagem e escritura podem produzir gestos que entrelaçam a estética e a política.
\end{abstract}

Palavras-chave: Imagem. Palavra. Artes gráficas. Artes visuais. Estética e política.

\section{Aproximaciones Entre Imagen Y Palabra En Las Artes Gráficas Y Visuales}

\begin{abstract}
Resumen
Esta comunicación propone un estudio de las posibles relaciones entre imagen y palabra en las artes gráficas y visuales, principalmente a partir de las transformaciones técnicas en los medios de reproducción gráfica a finales del siglo XIX, con el perfeccionamiento de la litografía y de la cromalitografía, y de los cambios en el arte en el arte a principios del siglo XX, con la disolución de los límites entre los lenguajes artísticos. Refuerza una perspectiva de estudio de las relaciones entre los diferentes medios en que se valoran no sólo homologas y similitudes, sino también antagonismos y disonancias entre imagen y palabra. Prioriza el estudio de las interacciones entre los recursos visuales y verbales, así como los elementos pictóricos de la palabra y los elementos poéticos de la imagen, trayendo para nuestra reflexión trabajos de artistas como Jules Chéret, Pablo Picasso, Paul Klee, Georges Breque, Stéphane Mallarmé, entre otros.

Palabras clave: Imagen. Palabra. Artes gráficas. Artes visuales. Estética y política.
\end{abstract}

Recebido: 30/01/2019

Aceito: 05/04/2019

\footnotetext{
* Universidade Federal de Minas Gerais (UFMG). Doutorando em Comunicação Social pela Universidade Federal de Minas Gerais, com bolsa parcial da CAPES (2017) e da FAPEMIG (2019/1).

** Universidade Federal de Minas Gerais (UFMG). Doutora em Comunicação Social pela UFMG e Professora do Departamento de Comunicação dessa mesma instituição, atuando na Graduação e Pós-graduação. Bolsista de Produtividade em Pesquisa do CNPq, PQ-2.
} 


\section{Introdução}

Antes da escrita, a vida era registrada por meio de imagens. As pinturas rupestres eram a forma de "registro do conhecimento" da pré-história. O historiador de arte Ernest Hans Gombrich (2008, p. 53) destaca que, nas primeiras civilizações, a criação de imagens, além de seu vínculo místico e religioso, também era uma primeira forma de escrita. Para estudiosos, como Anne-Marie Christin (1995, p. 5), a escrita nasceu da imagem, e "seja qual for o sistema escolhido, o do ideograma ou do alfabeto, sua eficácia procede unicamente dela". Por essa origem na imagem, a escrita pode ser considerada, em sentido estrito, como veículo gráfico da palavra. Gombrich (2008, p. 53) reforça essa tese ao recomendar que, mesmo que se saiba pouco a respeito dessas origens, para melhor compreender a arte, "será conveniente recordar, vez por outra, que imagens e letras são na verdade parentes consanguíneos."

Horácio, em sua Arte Poética, defende a irmandade entre a poesia e a pintura, chamando a pintura de "poesia muda" e a poesia de "pintura falada" (SCHOLLHAMMER, 2007, p. 12). Imagens e palavras podem expressar essencialmente a mesma ideia, embora por meios diferentes. Contudo, muito mais do que pensar acerca das especificidades desses dois regimes de expressão, refletimos aqui acerca dos modos como os entrelaçamentos entre texto e imagem podem acontecer. Sob esse aspecto, tanto Didi-Huberman $(2011,2017)$ quanto Rancière (2012) enfatizam a importância da montagem como possibilidade de encontro entre texto e imagem que recusa a linearidade causal, na qual acontecimentos são organizados narrativamente e evidenciados nas imagens que apenas reproduzem o que foi dito. Ao explicar sua noção de frase-imagem, Rancière (2003) primeiro questiona a lógica de que ao texto cabe o encadeamento das ações e que a imagem é apenas um suplemento de presença que dá carne e consistência ao texto. Para ele, a frase é que dá carne, sendo que a imagem se tornou potência ativa e disruptiva. Em segundo lugar, ao citar duas possibilidades de montagem entre texto e imagem, ele faz a distinção entre montagem dialética - caracterizada pela produção de choques entre elementos heterogêneos e pela encenação de "uma estranheza familiar, para fazer aparecer uma outra ordem que só se descobre pela via da violência e do conflito" (RANCIÈRE, 2003, p. 78) - e montagem simbólica - caracterizada pela aproximação de elementos heterogêneos via analogia e familiaridade, criando elos e convidando ao vínculo.

O que difere os autores é o modo como se apropriam da montagem no respectivo método que apresentam para discutir a política das imagens. Em Didi-Huberman (2017), a politicidade da montagem parece obedecer a um exercício metodológico de criar, ao mesmo tempo, intervalos e constelações, que funcionam como novas maneiras de dispor e pensar as coisas, desmontando ordens legitimadas. É nas constelações que vários elementos adquirem novo sentido e permitem a emergência de um texto histórico, organizado não sob a linearidade cronológica, mas sob o signo de uma vinculação dialética entre passado e presente. Por sua vez, em Rancière, a politicidade da montagem não se associa tanto a um embaralhamento e a uma intervenção direta dos enunciados, mas à escolha de outro enquadramento para "ler" os enunciados, sem intervir diretamente sobre eles. Ele afirma que montagens dialéticas devolvem a politicidade às imagens ao configurarem barreiras e distanciamentos entre a representação e o público, permitindo um curto-circuito no continumm pretensamente existente entre a ativação das emoções (passibilidade) e ação prática de intervenção. Segundo ele, "essa suspensão forja um olhar livre de ter que responder às solicitações que educam a maneira ordinária de ver e de habitar um mundo" (RANCIÈRE, 2006, p. 160). 


\section{Imagem e palavra nas artes gráficas e visuais}

A história da escrita nos mostra como imagem e palavra possuem vínculos estreitos desde a préhistória. As manifestações da arte pré-histórica são escritas que podem nos mostrar algo da vida e do pensamento das mulheres e dos homens das cavernas (PROUS, 1983, p. 11). A imagem de uma mão pintada nas pedras, por exemplo, feita há mais de 37 mil anos na Gruta de El Castillo, na Espanha, pode ser uma forma de escrita e registro pré-histórico, a marca da humanidade para a posteridade.

Exemplos de diversas épocas e culturas podem ser apontados para mostrar a aproximação entre imagem e escrita, desde a pré-história com as pinturas rupestres, a Idade Média com os manuscritos medievais, passando pela Idade Moderna com as recém-descobertas técnicas de reprodução da época (a litografia e a cromalitografia) ${ }^{1}$, até a atualidade com as várias possibilidades da editoração eletrônica. Ideias foram expressas por meio de imagens não só nos hieróglifos egípcios, mas também nos primeiros alfabetos e principalmente na escrita ideogramática do mundo oriental, por meio de uma longa tradição simbólica (PRAZ, 1982, p. 2).

Segundo Andrew Robinson (1995 apud VENEROSO, 2012, p. 82), escritas como a chinesa e a japonesa utilizam símbolos fonéticos para representar sons e símbolos que ocupam o lugar de palavras e ideias, conhecidos como logogramas ou ideogramas. Quanto mais ideogramática uma escrita mais pictórica ela será e, ao contrário, quanto mais fonética mais aproximada dos sons da fala. "O ideograma é letra mas também é desenho e no mundo islâmico a letra faz-se imagem.” (VENEROSO, 2012, p. 30). Algumas civilizações orientais não separaram as informações fornecidas pela imagem daquelas fornecidas pelos sistemas de escrita, como se pode observar na escrita ideogramática, claramente mais pictórica, de vários povos orientais:

[...] o ideograma é constituído de partes que sugerem uma relação entre si; é uma colagem onde cada elemento, trazendo ecos de sua forma original, contribui para a formação de um novo significado; não é uma somatória, é um processo de aglutinação. Talvez seja por isso que, enquanto expressão, extrapola o contexto linguístico e torna-se elemento plástico, linguagem visual. (MEDEIROS, 1996, p. 278).

Um sistema de escrita como o ideogramático supera o âmbito do estritamente linguístico e também se expressa em uma dimensão plástica, extrapolando as limitações impostas pelo pensamento histórico e linear comum ao ocidente, que sempre separou os termos pela lógica binária de "ou uma coisa ou outra". Na civilização oriental, a escrita é "uma coisa e outra", ou seja, ela é interseção e aglutinação entre visual e verbal. Roland Barthes (1990) parece confirmar essa percepção ao explicar que, na civilização oriental, "o que é traçado é o que está entre a escrita e a pintura" (BARTHES, 1990, p. 96), ou seja, o "traçado" é uma interseção entre pintura e escrita, logo, pelo pensamento oriental, não há sentido em pensar a anteposição da palavra sobre a imagem, já que uma comunga com a outra.

$\mathrm{Na}$ cultura ocidental procurou-se tratar as duas coisas de forma separada, principalmente a partir do Renascimento, quando houve um direcionamento do pensamento em função de uma explicação racionalista cada vez mais compartimentada. Com o fim dos manuscritos medievais e o surgimento da imprensa, ${ }^{2}$ outro tipo de vínculo se estabeleceu entre imagem e escrita. A partir do Renascimento,

1 A impressão litográfica possibilitou a reprodução em grandes formatos e a criação de letras próprias para cada peça gráfica, tendo sido criada em 1796 por Alois Senefelder. Com o passar dos anos, a técnica litográfica foi sendo aperfeiçoada e em 1848 já eram impressas dez mil folhas por hora. Nesse processo de aperfeiçoamento, foi criada a cromolitografia, patenteada pelo francês Godefroy Engelmann, em 1837, e versão em cores da litografia. O artista Jules Chéret foi um dos artistas que a aperfeiçoaram, o que possibilitou o uso de cores mais brilhantes e do degradê. A difusão dessa técnica foi uma das grandes responsáveis pelo desenvolvimento das artes gráficas, em especial a linguagem gráfica do cartaz no final do século XIX.

2 O termo "imprensa" deriva da prensa móvel, processo gráfico aperfeiçoado por Johannes Gutenberg no século XV e que, a partir do século XVIII, foi usado para imprimir jornais, então os únicos veículos jornalísticos existentes. 
nota-se uma nova relação entre a escrita e a imagem com o desenvolvimento da ilustração. "Surge então uma relação de dependência e subordinação da imagem ao texto" (VENEROSO, 2012, p. 8081). Com a invenção da imprensa, palavras e imagens passaram a ser reproduzidas por sistemas de impressão diferentes: os textos em tipografia ${ }^{3}$ e as imagens em xilogravura ${ }^{4}$ ou gravura em metal, ${ }^{5} \mathrm{o}$ que favoreceu para o distanciamento das duas mídias.

Contudo, apesar da estruturação do pensamento ocidental, que não apenas separou texto e imagem mas também atribuiu menor valor à imagem, subordinando-a ao texto, houve toda uma grande evolução e expansão dos meios de produção e difusão das imagens em conjunto com as palavras. As transformações nos meios de reprodução da imagem e da palavra a partir do século XIX em conjunto com as mudanças na arte do século XX, ao misturarem os espaços do texto e da imagem, produziram uma colisão entre essas duas mídias.

Apesar da adoção do texto como meio oficial de representação e estruturação do pensamento no ocidente, as imagens e seus meios de difusão estão cada vez mais presentes no cotidiano, ganhando importância crescente e espalhando-se por todos os lugares. As imagens propagam-se pela mídia impressa e eletrônica sob a forma de revistas, livros, panfletos, jornais e cartazes. Compõem a proposta pedagógica de enciclopédias, cartilhas, manuais, livros didáticos e apresentações multimídia. As imagens expandem-se em grandes dimensões nos outdoors publicitários que margeiam o tráfego nas ruas das cidades e serializam-se em lambe-lambes que disputam espaço com os grafites nos muros dessas mesmas cidades. As superfícies brilham em dispositivos eletrônicos portáteis, em displays de cristal líquido nas vitrines, em aeroportos, estações, salas de espera, halls de entrada, corredores de saída, plataformas de acesso, aviões, navios, ônibus, trens, elevadores etc. As imagens ofuscam multidões em imensos painéis eletrônicos que se erguem em estádios e escalam as fachadas dos prédios (BORGES, 2011, p. 45).

Além dessa difusão cada vez maior das imagens, também houve uma ampliação das possibilidades plásticas de manipulação visual dos textos e dos signos alfabéticos, fazendo surgir linguagens híbridas, impregnadas pelas misturas entre palavras e imagens. Um exemplo disso é a editoração eletrônica de textos e imagens em softwares gráficos. Nos cartazes, no tempo em que se utilizava a tipografia para compor as informações, as possibilidades técnicas de interação entre os tipos e as imagens eram muito limitadas, fazendo com que a delimitação entre a mancha de texto e as áreas reservadas às imagens fosse mais definida. Atualmente, a manipulação digital permite não apenas a justaposição entre textos e imagens, mas toda forma de variação dos textos, alterando seus tipos, dimensões e cores, combinando-os ou fundindo-os com os elementos pictóricos.

\footnotetext{
3 A tipografia tem sua origem principal nas primeiras impressões com tipos gráficos (letras em relevos confeccionadas em madeira, barro ou ferro) e passou também a ser um modo de se referir à gráfica que usa uma prensa de tipos móveis. 4 Técnica de origem chinesa em que o artesão utiliza um pedaço de madeira para entalhar um desenho, deixando em relevo a parte que pretende fazer a reprodução. Em seguida, utiliza tinta para pintar a parte em relevo do desenho. Na fase final, é utilizado um tipo de prensa para exercer pressão e revelar a imagem no papel ou outro suporte. Um detalhe importante é que o desenho sai ao contrário do que foi talhado, o que exige maior trabalho do artesão e mais dificuldade para a reprodução de textos.

5 Processo de gravura feito numa matriz de metal, geralmente o cobre, conhecida na Renascença. Pode também ser feita em alumínio, aço, ferro ou latão amarelo. Esse processo também inverte a imagem na impressão, dificultando a reprodução de textos.
} 
Figura 1 - 30 Posters on environment and development - 1992

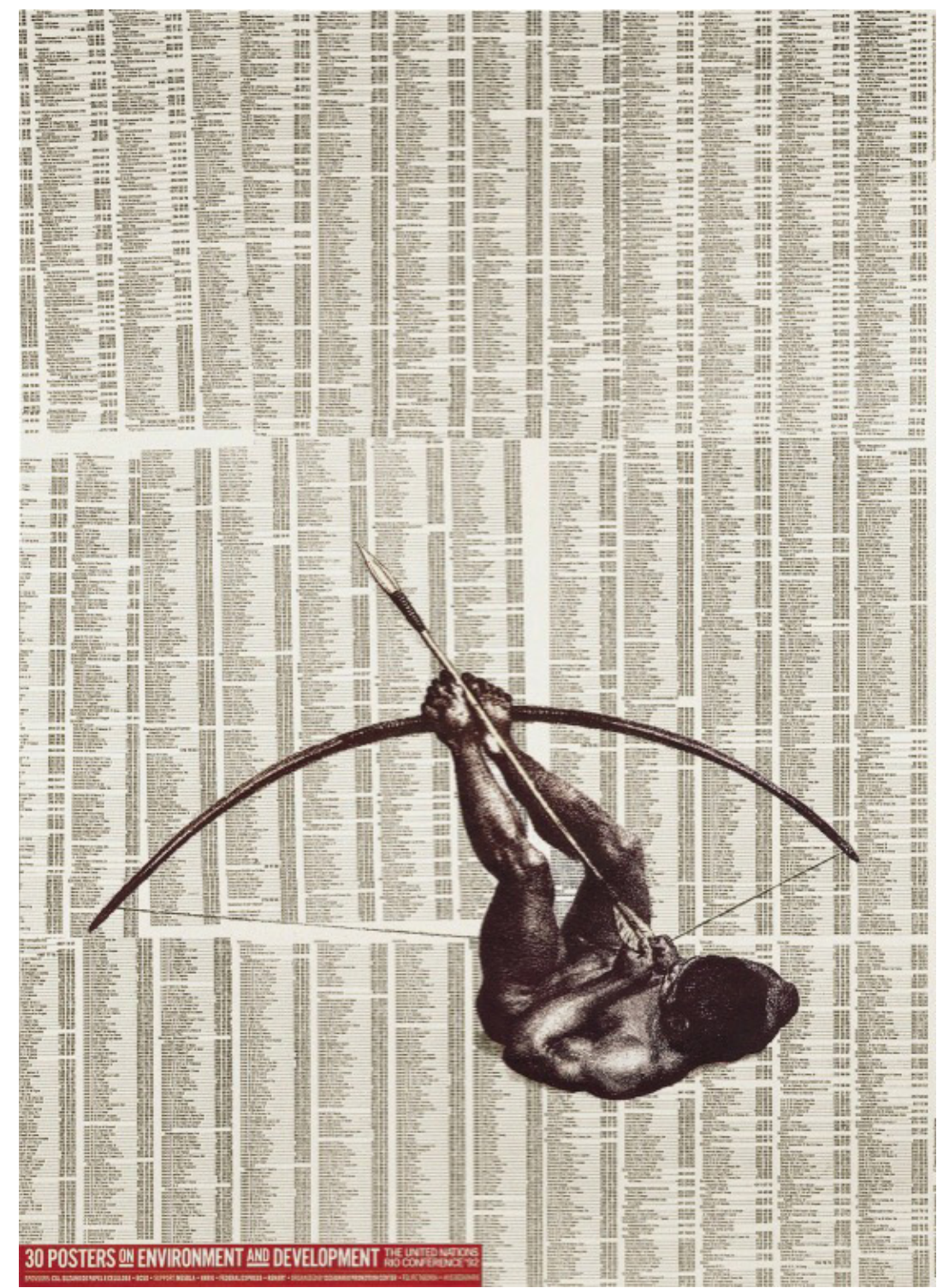

Fonte: SACCHETTA, 2012, p. 652.

Michel Butor (1992, p. 32) afirma que, no plano de sua atuação, existem três níveis de relação entre a imagem e o texto: a crítica de arte, quando "fala-se de um quadro, ou de um pintor, então o texto vai convidar a olhar, vai comentar o que se vê etc.". Um segundo sentido seriam os livros ilustrados e os livres de peintres, que trazem colaborações entre artistas e poetas: "aqui se veem duas coisas ao mesmo tempo, o texto e a imagem, enquanto que na crítica de arte se está livre, pode-se olhar a imagem e ler o texto em outra página." (BUTOR, 1992, p. 32). E um terceiro nível, "quando o texto intervém no interior mesmo da imagem e aqui existe uma diferença, porque o texto funciona também como uma imagem" (BUTOR, 1992, p. 32). Isso ficou bastante evidente com o desenvolvimento das técnicas de reprodução, como a litografia e a cromalitografia, que permitiram que a letra fosse desenhada pelo artista gráfico diretamente na matriz, a pedra, o que fez com que a imagem e a palavra fossem criadas e impressas pelo mesmo processo de impressão, readquirindo vínculos mais estreitos.

A litografia revolucionou os meios de reprodução gráfica pelo uso de cores, pela possibilidade de produção em massa e pela retomada da interação estreita entre imagem e palavra. Antes do uso da litografia, os cartazes, por exemplo, eram produzidos com o uso de tipografia (HOLLIS, 2000, p. 5), ou seja, com matrizes em alto relevo para a impressão de letras, traços e algumas marcações e símbolos. Com a impressão litográfica surgiu a possibilidade da reprodução em grandes formatos e a criação de novas letras, próprias para cada peça gráfica, colaborando para a reaproximação entre texto e imagem. 
Figura 2 - Cartaz tipográfico Theatre Comique!- 1872.

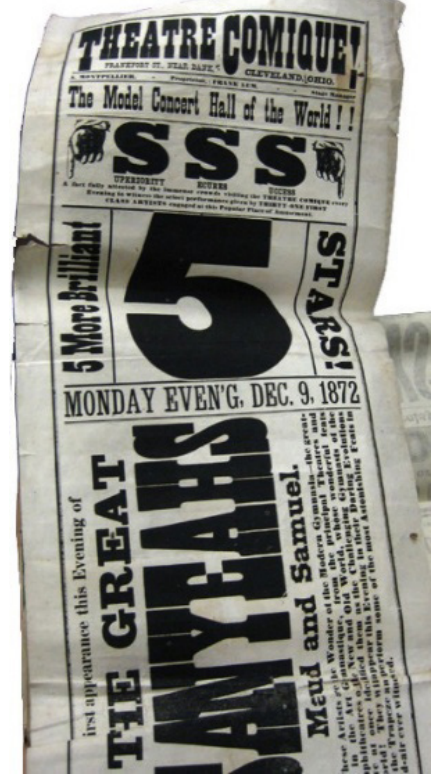

Fonte: Graphic Design History, 2018.

Hoje, na era da imagem digital, dos vídeos, da tecnologia cibernética e da reprodução eletrônica, o texto depende, mais do que nunca, de sua qualidade visual, da materialidade da escrita, de seu aspecto gráfico. Da mesma maneira, dificilmente uma imagem representa sentido em função de sua pura visibilidade. Em outras palavras, já não podemos mais tratar a imagem como ilustração da palavra nem o texto como explicação da imagem. "É o conjunto texto-imagem que, ao formar um complexo heterogêneo, se torna o objeto fundamental para a compreensão das condições representativas em geral." (SCHOLLHAMMER, 2007, p. 17).

Figura 3 - Cartas de Elisabet Vogler a seu filho - 2003

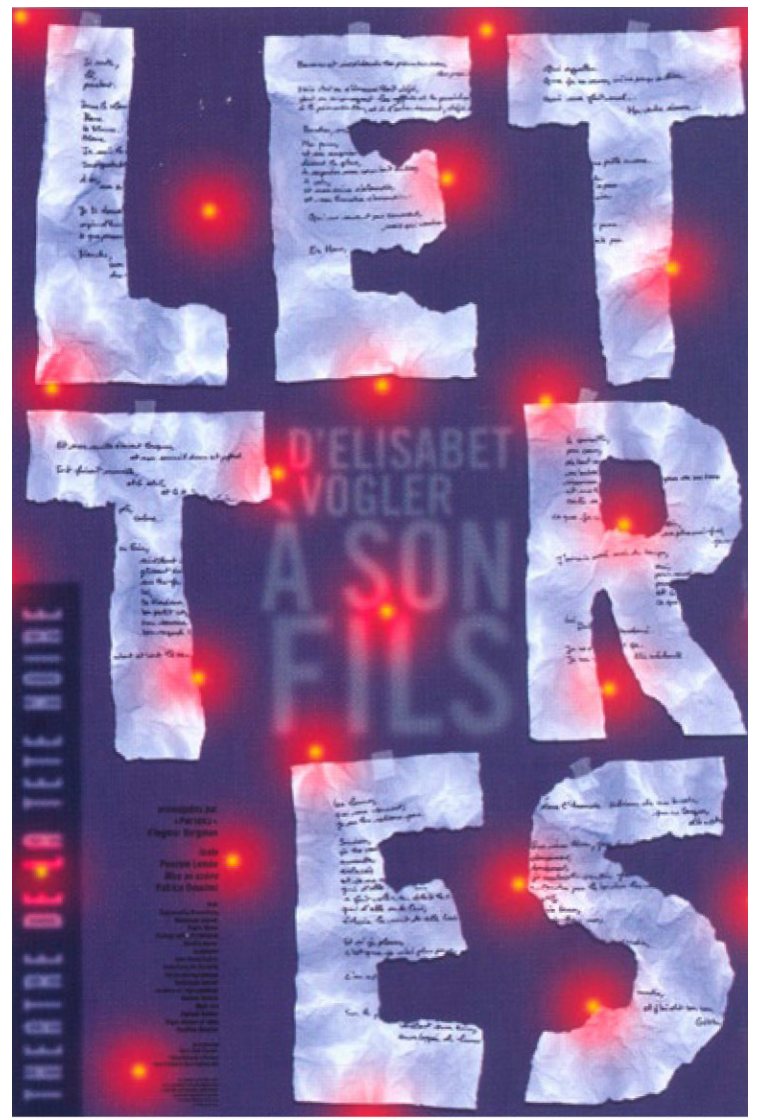

Fonte: BORGES, 2011, p. 47. 
Sob esse aspecto, a frase-imagem e a montagem dialética propostas por Rancière (2003) transformam e reenquadram as fórmulas estéticas que nomeiam os universos de experiência, que definem formas consensuais ou dissensuais de produzir e negociar sentidos. O que interessa a este autor é uma construção combinada entre historicidade e atemporalidade, na busca por um modo de enquadrar e pensar enunciados, objetos e acontecimentos em termos de multitemporalidade, de enredos entrelaçados por uma operação de montagem que desfaça a relação de submissão entre texto e imagem. O que Rancière (2012, p. 45) propõe é olhar para as formas tradicionais de escritura da história - as formas de apresentação das situações, de agenciamento dos enunciados, as formas de construção das relações entre causa e efeito ou entre antecedente e consequente - de outro jeito, "rasgando os formatos tradicionais de apresentação dos fatos". Assim, Rancière nos apresenta uma concepção política das imagens e dos textos, na reivindicação do caráter poético e estético de todo enunciado, quebrando as fronteiras e as hierarquias entre os níveis de discurso.

Essa proposta nos permite potencializar tanto o gesto de pensar a política pelas imagens, quanto aquele de pensar a política das imagens. Afinal, como nos alerta Rancière (2012, p. 96), "uma imagem nunca está sozinha. Pertence a um dispositivo de visibilidade que regula o estatuto dos corpos representados e o tipo de atenção que merecem".

Este autor procura enfatizar que os arranjos que buscam (no dispositivo de causalidade) neutralizar as resistências nas imagens podem ser abalados pela emergência da figuração. Ao contrário da representação pautada pela causalidade determinística, a figuração "é um sistema de relações entre semelhança e dessemelhança que põe em jogo vários tipos de intolerável” (RANCIÈRE, 2012, p. 93). A figuração que surge das operações de montagem entre frase e imagem é responsável pela descontinuidade, pela evidenciação de um hiato que desnaturaliza o olhar e nos permite apreender "outras realidades, outras formas de senso comum, ou seja, outros dispositivos espaço-temporais, outras comunidades de palavras e coisas, formas e significados." (RANCIÈRE, 2012, p. 99). A política presente no gesto figurativo relaciona-se com a capacidade que as imagens, em relação dialética com as palavras, possuem de "mudar os lugares e a forma de contagem dos corpos" (RANCIÈRE, 2012, p.95), devolvendo à experiência sua potencialidade criativa e compartilhável.

Rancière (2006) afirma que a importância da escrita e da leitura não está necessariamente na produção do conteúdo das mensagens e representações, mas sua associação a um outro regime sensível que conecta o sujeito a uma comunidade mais ampla de atos de pensamento e criação, de palavra e de escuta que se chamam e se respondem. O que a figuração alcança com a montagem entre a letra e a imagem é também a capacidade de se conectar a uma comunidade sensível que não se vincula necessariamente à classe social, mas permite pequenas invenções no ato mesmo de fazer circular histórias, objetos e enunciados, multiplicando as racionalidades disponíveis no gesto de conferir uma forma singular à capacidade de fazer e dizer que pertence a todos.

\section{Imagem e palavra no cartaz moderno}

Com as mudanças do século XIX ocorreu o aparecimento do cartaz moderno, impulsionado pelo aprimoramento da litografia e de sua utilização na produção de peças gráficas iniciada por Jules Chéret. Com isso, as cidades e seus signos, marcas e grafismos dos anúncios de rua passam a assumir um lugar de importância na arte do século seguinte, especialmente na França. As técnicas de impressão tiveram, nessa época, um aperfeiçoamento extraordinário não só em relação à letra mas também em relação à reprodução da imagem. O surgimento e o aprimoramento da litografia simplificou consideravelmente os procedimentos da gravura, possibilitando a impressão em cores, que antes não era possível, o que levou essa técnica a ser bastante utilizada em sua forma comercial. 
Apesar da existência de diferenças entre a litografia industrial/comercial e a litografia artística, pode-se notar um diálogo entre ambas. Vários foram os artistas em atividade no final do século XIX e início do século XX que produziam tanto litografias artísticas quanto cartazes e ilustrações. Pode-se citar como exemplos, Édouard Manet, Toulouse-Lautrec e ainda Jules Chéret, muito conhecido pelos seus cartazes e que teve grande influência sobre o Art-Nouveau. Em 1888 Chéret começou a produzir, em Paris, cartazes litográficos com sua própria prensa. (VENEROSO et al., 2004, p. 65).

\section{Figura 2 - Bal du Moulin Rouge - Jules Chéret - 1889}

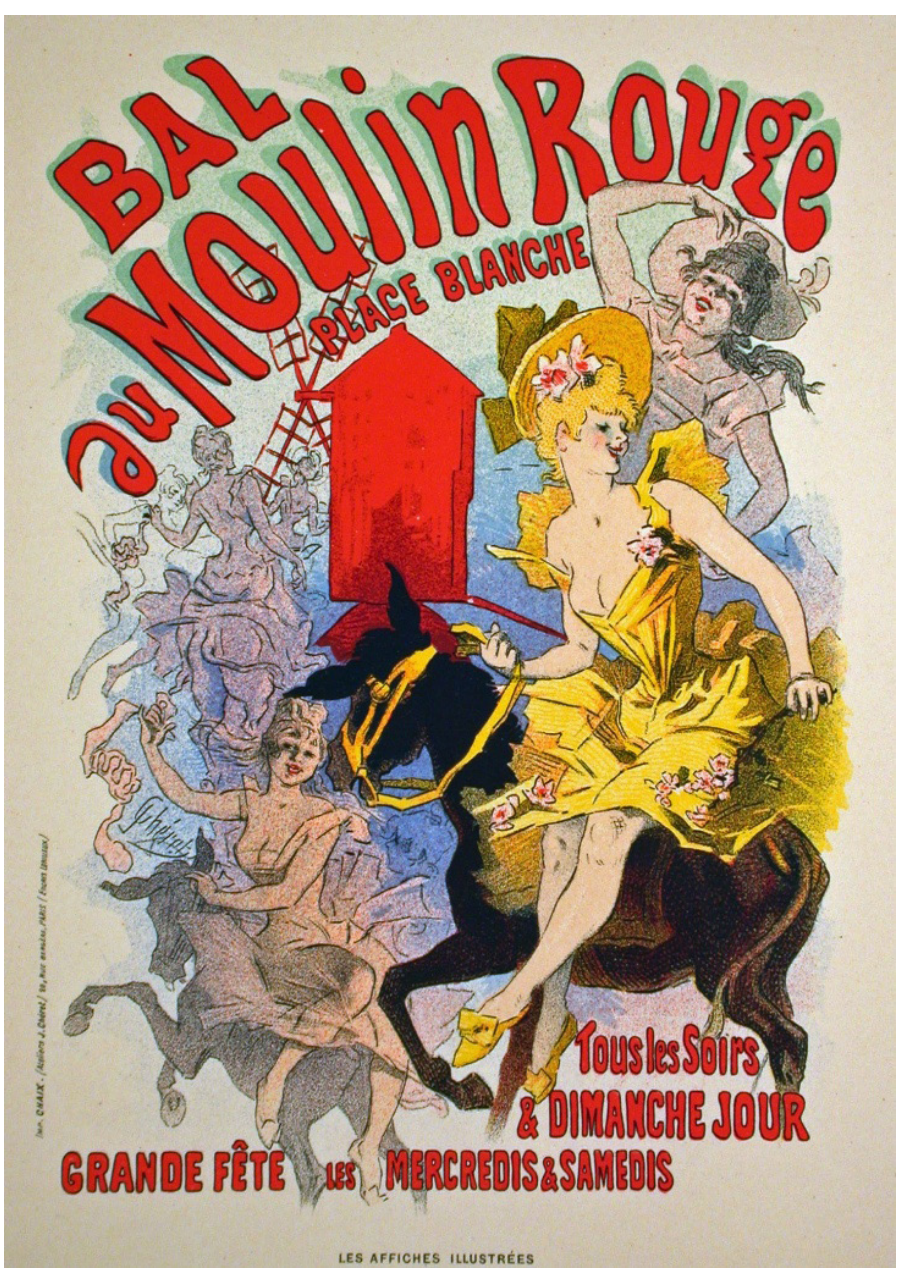

Fonte: Coleção de Jim e Sue Wiechmann, Milwaukee Art Museum

Chéret desenhava diretamente sobre a pedra litográfica, devolvendo à litografia essa característica de meio direto de criação que ela já tinha possuído com Francisco de Goya e outros artistas do começo do século XIX. A litografia tinha sido utilizada, em geral, simplesmente como um procedimento para reproduzir outras formas de expressão artística. Com Chéret, ela recupera, portanto, sua autonomia como linguagem gráfica (BARNICOAT, 1973, p. 7-8).

Nota-se que letras e imagens têm participação ativa na composição dos cartazes dessa época. As letras, em geral, eram desenhadas diretamente sobre a pedra litográfica e havia um alto grau de criação e adaptação das letras realizadas pelos desenhistas-litógrafos nas chamadas "letrasfantasia". Algumas vezes eram desenhadas com a utilização de gabaritos e, em outros casos, eram desenhadas a mão livre (VENEROSO et al. 2004, p. 66).

Esse diálogo entre o desenho da letra e o desenho das imagens no final do século XIX está relacionado às possibilidades técnicas abertas pela litografia. Comparada à gravura em metal e à xilogravura, técnicas muito usadas para a realização de ilustrações, a litografia possui vantagens. $\mathrm{Na}$ xilogravura, o desenho da letra era extremamente problemático quando realizado junto à 
imagem, já que qualquer erro com a goiva ${ }^{6}$ significava a perda total da matriz. Na gravura em metal, a impossibilidade do uso da letra junto à imagem era maior que na xilogravura, pela própria limitação da técnica.

Na criação de cartazes é essencial trabalhar palavra e imagem de maneira integrada, de modo que essa relação seja entrelaçada e combinada. Na definição apresentada por Richard Hollis (2000, p. 5, grifo nosso) "o cartaz pertence à categoria da apresentação e da promoção, na qual imagem e palavra precisam ser econômicas e estar vinculadas a um significado único e fácil de ser lembrado.". Abraham Moles (1974) define o cartaz como uma "imagem, em geral colorida, contendo normalmente um único tema e acompanhado de um texto condutor." (MOLES, 1974, p. 44, grifo nosso). A definição de cartaz, apresentada por Harold F. Hutchinson em 1968, possui sentido próximo daqueles apontados pelos autores anteriores, corroborando com a compreensão de que o cartaz é a mídia que se mostra ao público como

um anúncio grande, normalmente com um elemento pictórico, normalmente impresso em papel e normalmente exposto em uma parede ou quadro para o público em geral. Seu objetivo é chamar a atenção para qualquer coisa que o anunciante esteja tentando promover e gravar uma mensagem no transeunte. O elemento visual ou pictórico proporciona a atração inicial - e ele dever ser suficientemente impressionante para prender o olhar do transeunte e superar a atração concorrente dos outros cartazes, de modo que precisa de uma mensagem verbal suplementar que reforce e amplifique o tema pictórico. O tamanho grande da maioria dos cartazes permite que a mensagem verbal seja lida claramente à distância. (HUTCHINSON, 1968 apud SONTAG, 2010, p. 211, grifo nosso).

Com base nessas definições pode-se perceber, dentre outras coisas, que o cartazé predominantemente composto pela interação palavra/imagem. O cartaz é livre para agregar palavra e imagem, mesclando recursos linguísticos e pictóricos, bem como para escolher apenas um ou outro recurso, e, quando realizados somente com textos (cartazes tipográficos), estes assumem características de imagem.

\section{Imagem e palavra nas artes gráficas e visuais do final do século XIX e início do século XX}

No final do século XIX e início do século XX, a escrita (a letra, a palavra, o texto) irrompe no espaço do quadro e integra-se ao discurso plástico, passando a interferir no interior mesmo da imagem e funcionando também como elemento pictórico. Paul Klee, entre outros, seria um dos artistas a abolir a soberania do princípio que estabelece a distinção entre representação plástica e referência linguística

ao colocar em destaque, num espaço incerto, reversível, flutuante (ao mesmo tempo tela e folha, toalha e volume, quadriculado do caderno e cadastro da terra, história e mapa), a justaposição das figuras e a sintaxe dos signos. Barcos, casa, gente, são ao mesmo tempo formas reconhecíveis e elementos de escrita. (FOUCAULT, 1989 apud VENEROSO et al, 2004, p. 68).

Pode-se fazer um paralelo entre o que ocorreu nas artes plásticas no início do século XX e o que ocorreu nos cartazes com o desenvolvimento da litografia no século XIX. Nos dois casos notase a integração entre texto e imagem, que pode ser relacionada com a integração que existia nos manuscritos medievais, onde a letra, escrita à mão, era ela própria imagem, além de se relacionar estreitamente com as iluminuras. Assim, a volta da letra manuscrita retoma essa característica de "coisa desenhada".

6 Goiva é o nome dado a uma série de instrumentos cortantes utilizados para o entalhe em madeira. 
A reaproximação palavra/imagem na arte do século XX pode ser vista como um dos resultados da quebra de fronteiras e da mescla de linguagens artísticas que ocorreu de maneira recorrente e não linear iniciados no final do século XIX e durante todo o século XX. Nesse processo de resgate de vínculos entre a palavra e a imagem, tiveram grande importância as experiências do poeta francês Stéphane Mallarmé e o trabalho pioneiro de Pablo Picasso e Georges Braque, com os papiers collés que inauguram uma forte tendência da arte contemporânea, incorporando na obra artística materiais não artísticos: letras, fragmentos retirados de jornais, partituras musicais, papéis de parede etc.

Figura 3 - Estudo de layout do poema Un coup de dés - Stéphane Mallarmé - 1896

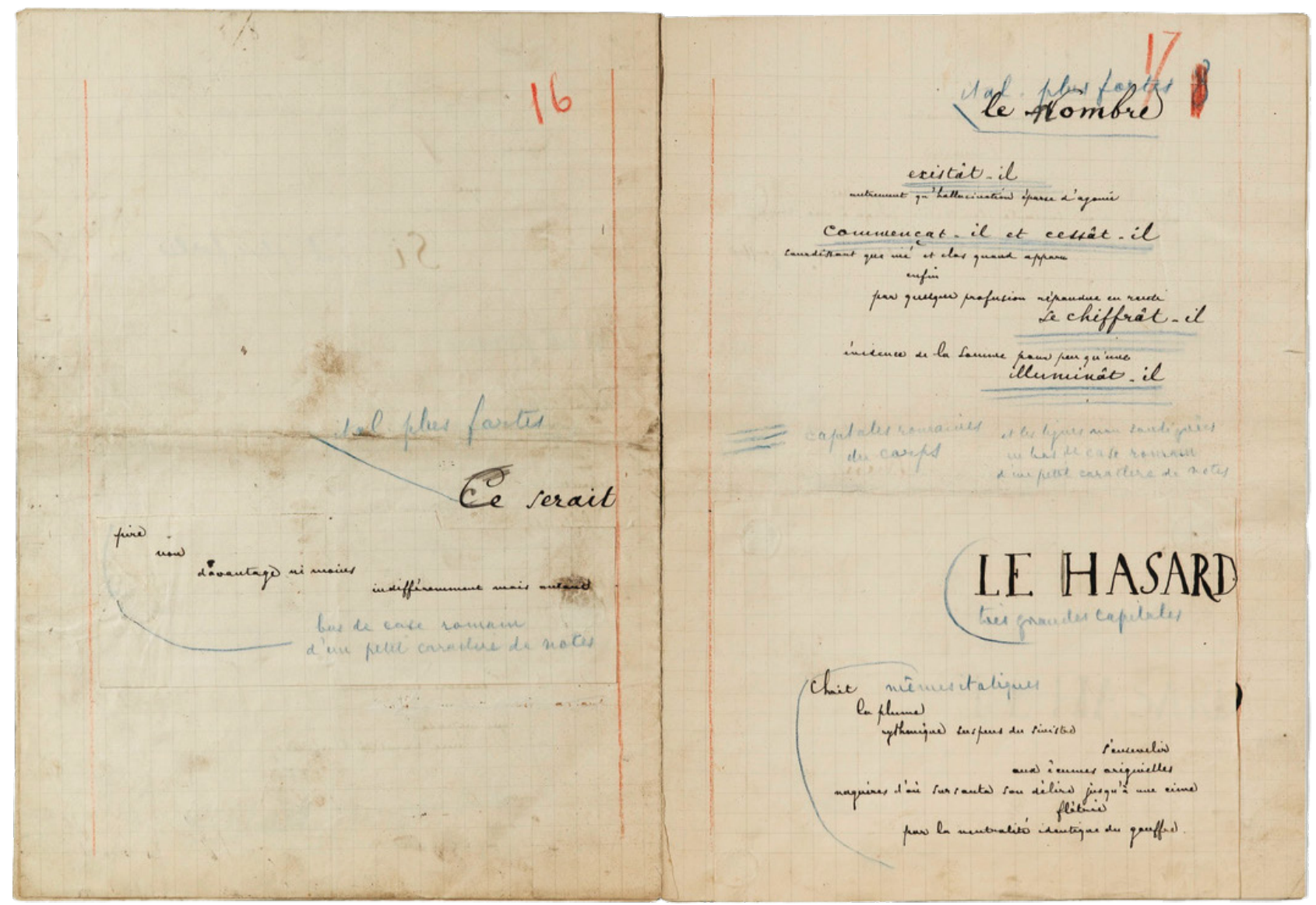

Fonte: WIKIPEDIA, 2018.

Esses e outros artistas, seja no campo da literatura ou das artes plásticas, tiveram contato com a produção gráfica do final do século XIX, afetada pela rápida transformação dos processos, das linguagens e da proliferação de novas famílias tipográficas (VENEROSO, 2006, p. 148-149). Junto a isso, o encurtamento das distâncias pela comunicação e pelos transportes contribuiu para novas percepções das relações espaço/temporais naquela época. A colagem de fragmentos de letras, partituras, tíquetes e jornais, interagindo com outros elementos na obra de arte cubista, conferiram textura ao quadro por sua ênfase no aspecto formal e plástico; no entanto, expressam também uma preocupação de ordem contextual, pelo menos nos papiés collés de Picasso, já que é possível identificar certa seleção nos fragmentos de jornais empregados pelo artista no tocante aos temas das notícias. O condicionamento das letras ao plano acentuava o caráter de superfície da tela, rompendo com a pintura tradicionalmente ilusionista/representativa e suas profundidades fictícias, alçando esta arte uma dimensão gráfica, em que os signos verbais, arrancados de seu contexto funcional de comunicação, ganham autonomia enquanto uma realidade em si, permitindo-se serem perpassados por múltiplos e novos significados (VENEROSO, 2006, p. 150). 
Figura 4 - Violino, vidro, jornal, garrafa - Picasso - 1896

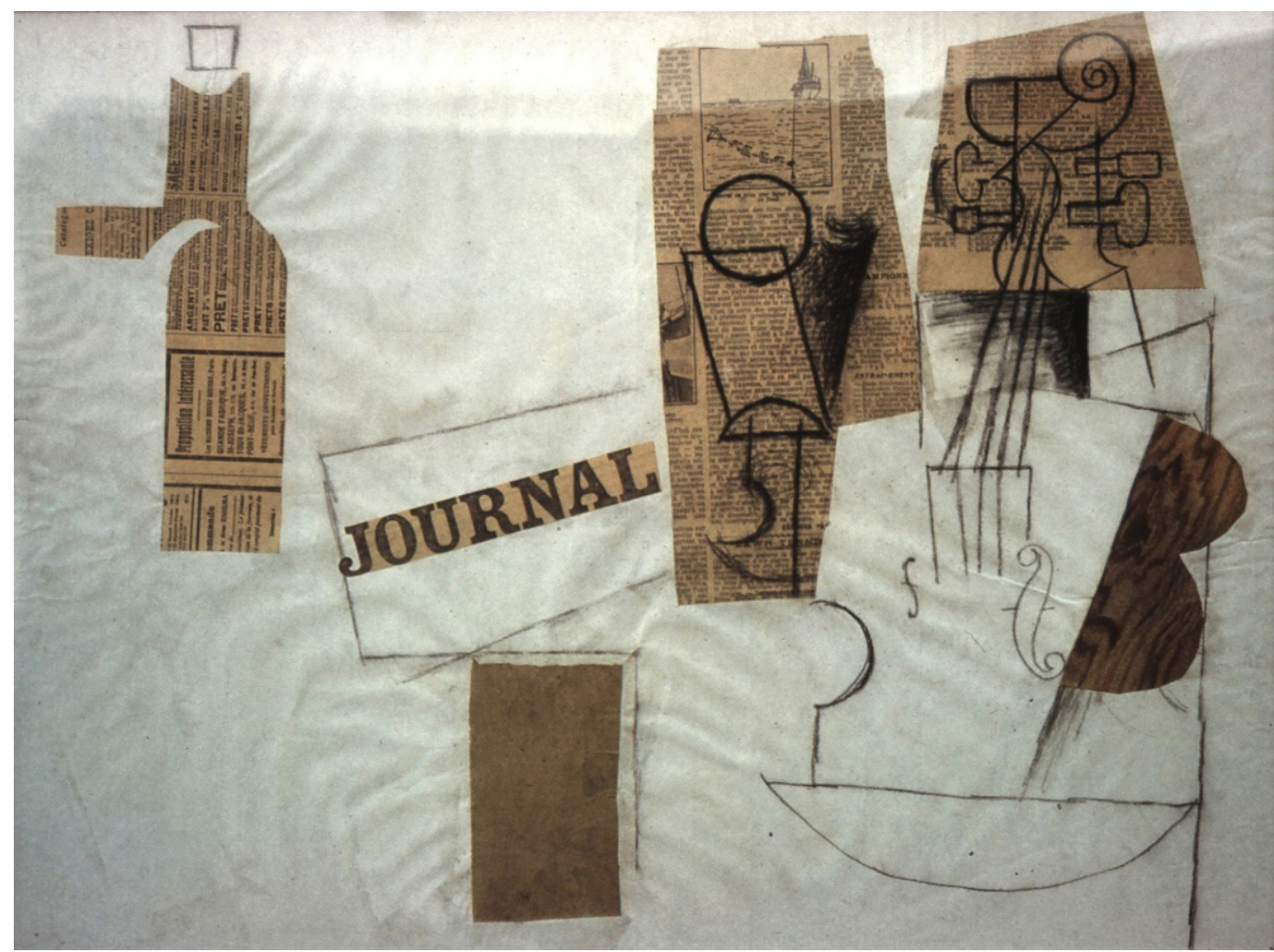

Fonte: DAVID CARR-SMITH, 2018.

Provavelmente, os experimentos gráficos do século XIX afetaram Picasso que, atraído por seu vigor visual e por suas qualidades plásticas, passou a incorporá-los em seus trabalhos. Dentro do espaço cubista, ele usa recursos tipográficos como elementos integrantes da composição. Com isso, ele restituiu às letras sua visualidade plástica: elas não estão ali para comunicar uma mensagem, pois têm um sentido de construção formal. Tudo isso, é claro, aliado ao espírito de pesquisa de Picasso, que mostra uma atitude não-convencional ao utilizar, em seus trabalhos, materiais pobres e sem o status "artístico". O impacto dessa atitude foi tão grande, que esse se tornou um procedimento usual na arte do século XX, surgindo de novo em movimentos como o Dadaísmo, a Pop art e até na arte contemporânea.

É importante aqui lembrar os experimentos gráficos que floresceram no século XIX e que deixaram sua marca não só nas artes visuais e gráficas, mas também na literatura. Vários artistas atuantes entre 1880 e 1920 tiveram uma ligação profissional com as artes gráficas, produzindo cartazes e desenhos de publicidade; entre eles, Henri de Toulouse-Lautrec, Pierre Bonnard e Aleksandr Rodchenko, parceiro do poeta Vladimir Maiakovski em vários projetos publicitários durante a década de 1920.

Para encerrar, se retormarmos as influências desses experimentos gráficos sobre o cartaz, veremos como suas características - formais e temáticas - transformaram-se ao longo dos séculos XIX e XX, acompanhando as mudanças dos meios de comunicação e dos movimentos artísticos. Também se encontra no cartaz um tom próprio: a caricatura, o exagero, a sátira, a paródia, o escândalo e o riso figuraram as produções de gerações de "cartazistas" (SZANIECKI, 2007, p. 11). A partir dessas transformações, o cartaz passa a atuar como meio e forma de "rebeldia", de contestação e de subversão da ordem institucionalizada (social e acadêmica), ampliando sua potencialidade política de afetar seu entorno cultural e social, assim como de ser afetado por ele. Deve-se, portanto, levar em conta as condições de produção/circulação/consumo dos discursos em jogo, examinando-se as determinações responsáveis pelas escolhas, conscientes ou não, feitas por ocasião do engendramento de um discurso e suas relações de poder, instituições sociais e identidades que regem e organizam sua criação, recepção e circulação. 
Desse modo, e esse é um tema para explorações futuras, um cartaz pode ser considerado como político quando deixa entrever as operações que influenciam na interpretação daquilo que vemos, ou seja, a potência política está tanto nas imagens (materialidade sígnica) quanto nas relações e operações que as definem em sua relação com a palavra. Rancière (2003) e Didi-Huberman (2017) nos revelam, respectivamente nos conceitos de frase-imagem e de montagem, como imagens e escritura contribuem para desenhar configurações novas do visível, do dizível e do pensável e, por isso mesmo, uma paisagem nova do possível.

\section{Considerações finais}

A escrita e a imagem relacionam-se à constante preocupação do homem, desde seus primórdios, em registrar os fatos, narrar os acontecimentos, representar o mundo material e espiritual, sejam eles relacionados a acontecimentos do cotidiano, como as caçadas, ou de ordem mítica e religiosa, como se acredita nas pinturas das cavernas, onde o homem viveu há milhares de anos.

Percebemos que as relações entre imagem e palavra nas artes gráficas e visuais sempre existiram, podendo ser mais ou menos estreitas dependendo da época, da cultura e dos avanços técnicos. Essa relação pode se dar de diferentes formas (pela referência de uma mídia à outra ou pela proximidade física entre as duas) e variados níveis (pelo grau de simbolicidade e iconicidade do texto, ${ }^{7}$ pelo grau de separabilidade entre imagem e palavra, ${ }^{8}$ pela autossuficiência de cada mídia ${ }^{9}$ e pela forma de imbricação entre texto e imagem ${ }^{10}$ (HOEK, 2003, p. 185). Contudo, não importa o período nem o tipo de relação entre imagem e palavra - predominância, subordinação ou mescla -, o que se nota a respeito das duas ao longo da história é sua constante presença como mediadoras gráficas de significado e a contaminação de uma pela outra. Para entender melhor essa movimentação, elaboramos uma reflexão com o intuito de identificar a visualidade da escrita e os possíveis diálogos entre imagem e palavra, principalmente a partir do final do século XIX, com os cartazes litográficos e sua influência nas linguagens artísticas no início do século XX, quando os limites precisos entre as linguagens artísticas e as separações entre imagem e palavra na cultura ocidental, pelo menos no âmbito das artes gráficas e visuais e da literatura, começaram a ser postas em xeque.

Esse diálogo e a aproximação entre as artes, a passagem de um modo artístico ao outro, reestabelecem o diálogo da escrita com a visualidade e reatam, de certa maneira, antigos vínculos existentes entre a palavra e a imagem, entre o traço do desenho e o traço da escrita, revelando que a escrita não é apenas um meio de transcrição da fala, mas uma realidade dupla, dotada de uma parte visual. É nesse lugar limítrofe, nessa margem em que a escrita e as artes confluem, que se encontra um espaço privilegiado para se pensar as possíveis relações - estéticas e políticas - entre imagem e palavra.

\footnotetext{
7 Simbolicidade: palavras e textos funcionam como elementos verbais, porém disfarçados em signos icônicos, por exemplo, as capitulares e a caligrafia. Iconicidade: palavras e textos perdem sua função verbal e ganham em plasticidade, sendo empregados um pouco à maneira das frutas de Arcimboldo, utilizadas na composição de seus retratos. (HOEK, 2006, p. 181-182).

$8 \mathrm{O}$ signo visual e o signo verbal pertencem a sistemas significantes diferentes e se deixam isolar um em relação ao outro.

9A coerência individual de um e de outro permanece intacta.

10 Transposição, justaposição, combinação ou fusão.
} 


\section{Referências}

BARNICOAT, John. Los carteles. Barcelona: Gustavo Gili, 1972.

BARTHES, Roland. O óbvio e o obtuso: ensaios críticos III. Rio de Janeiro: Nova Fronteira, 1990.

BORGES, Marcelo de Carvalho. Tessitura Visual da Palavra: Reflexões acerca dos aspectos plásticos das palavras na obra de Mira Schendel. 186 f. Dissertação (Mestrado em Artes) - Universidade Federal de Minas Gerais - UFMG, Belo Horizonte, 2011.

BUTOR, Michel. Repertório. São Paulo: Perspectiva, 1974.

CHRISTIN, Anne-Marie. L'image écrite: ou la déraison graphique. Paris: Flammarion, 1995.

DAVID CARR-SMITH. Design / Art / Kitsch / Change. Disponível em: http://www.davidcarrsmith. co.uk/_D-WW_20C-ART+AD1.htm Acesso em: 15 nov. 2018.

DIDI-HUBERMAN, Georges. Sobrevivência dos vaga-lumes. Tradução de Vera Casa Nova e Márcia Arbex. Belo Horizonte: Ed. UFMG, 2011.

DIDI-HUBERMAN, Georges. Quando as imagens tomam posição. O olho da história, 1. Belo Horizonte: Ed. UFMG, 2017.

FOUCAULT, Michel. Isto não é um cachimbo. Rio de Janeiro: Paz e terra, 1989.

GRAPHIC DESIGN HISTORY. Broadsides. Disponível em: <http://designhistory.org/Poster_pages/ Braodsides.html>. Acesso em: 15 nov. 2018.

GOMBRICH, Ernst Hans. A história da arte. Tradução de Álvaro Cabral. Rio de Janeiro: LTC, 2008.

HOEK, Leo_H. A transposição intersemiótica: por uma classificação pragmática. Tradução de Marcia Arbex. In: ARBEX, Marcia (Org.). Poéticas do visível. Belo Horizonte: FALE, UFMG, 2006, p. 167189.

HOLLIS, Richard. Design gráfico: uma história concisa. Tradução de Carlos Daudt. 2a. tiragem. São Paulo: Martins Fontes, 2000.

HUTCHINSON, Harold F. The poster, an illustratred history from 1860. Londres: Studio Vista, 1968.

MEDEIROS, Afonso. Pictograma, ideograma, metáfora visual. In: Congresso da ANPAP, 1996, Anais. Campo Grande, 1996. p. 273-281.

MOLES, Abraham. O cartaz. Tradução de Miriam Garcia Mendes. São Paulo: Perspectiva, Universidade de São Paulo, 1974.

PRAZ, Mario. Literatura e artes visuais. São Paulo: Cultrix/Edusp, 1982.

PROUS, André. Arte do Brasil na Pré-História. Ciência Hoje, v. II, n. 7, p. 10-17, jul./ago. 1983.

RANCIÈRE, Jacques. Le destin des images. Paris: La Fabrique, 2003.

RANCIÈRE, Jacques. Le coup double de l'art politisé: entretien avec Gabriel Rockhill. Lignes, v. 1, n. 19, p. 141-164, 2006.

RANCIÈRE, Jacques. O destino das imagens. Rio de Janeiro: Contraponto, 2012.

ROBINSON, Andrew. The history of writing. London: Thames and Hudson, 1995.

SCHOLLHAMMER, Karl Erik. Além do visível: o olhar da literatura. Rio de Janeiro: 7Letras, 2007.

SONTAG, Susan. Pôster: anúncio, arte, artefato político e mercadoria. In: BIERUT, Michael et al. Textos clássicos do design gráfico. Tradução de Fernando Santos. São Paulo: Martins Fontes, 2010. p. 210-235.

SZANIECKI, Barbara. Estética da multidão. Rio de Janeiro: Civilização Brasileira, 2007. 
VENEROSO, Maria do Carmo de Freitas et al. Antigas marcas, novas mídias: a arte humanizando as tecnologias. Relatório Final. Belo Horizonte: FAPEMIG, 2004. SHA-369/01.

VENEROSO, Maria do Carmo de Freitas. O diálogo imagem-palavra na arte do século XX: as colagens cubistas de Pablo Picasso e sua relação intertextual com os caligramas de Guillaume Apollinaire. In: Aletria: Revista de Estudos da Literatura. Belo Horizonte: Programa de Pós-Graduação em Letras: Estudos Literários, v. 14, jul./dez. 2006. p. 147-161.

VENEROSO, Maria do Carmo de Freitas. Caligrafias e escrituras: diálogo e intertexto no processo escritural nas artes no século XX. Belo Horizonte: C/Arte, 2012.

WIKIPÉDIA. Estudo de layout do poema Un coup de dés - 1896. Disponível em: <https:// pt.wikipedia.org/wiki/Un_Coup_de_Dés_Jamais_N\%27Abolira_le_Hasard $>$. Acesso em: 15 nov. 2018. 